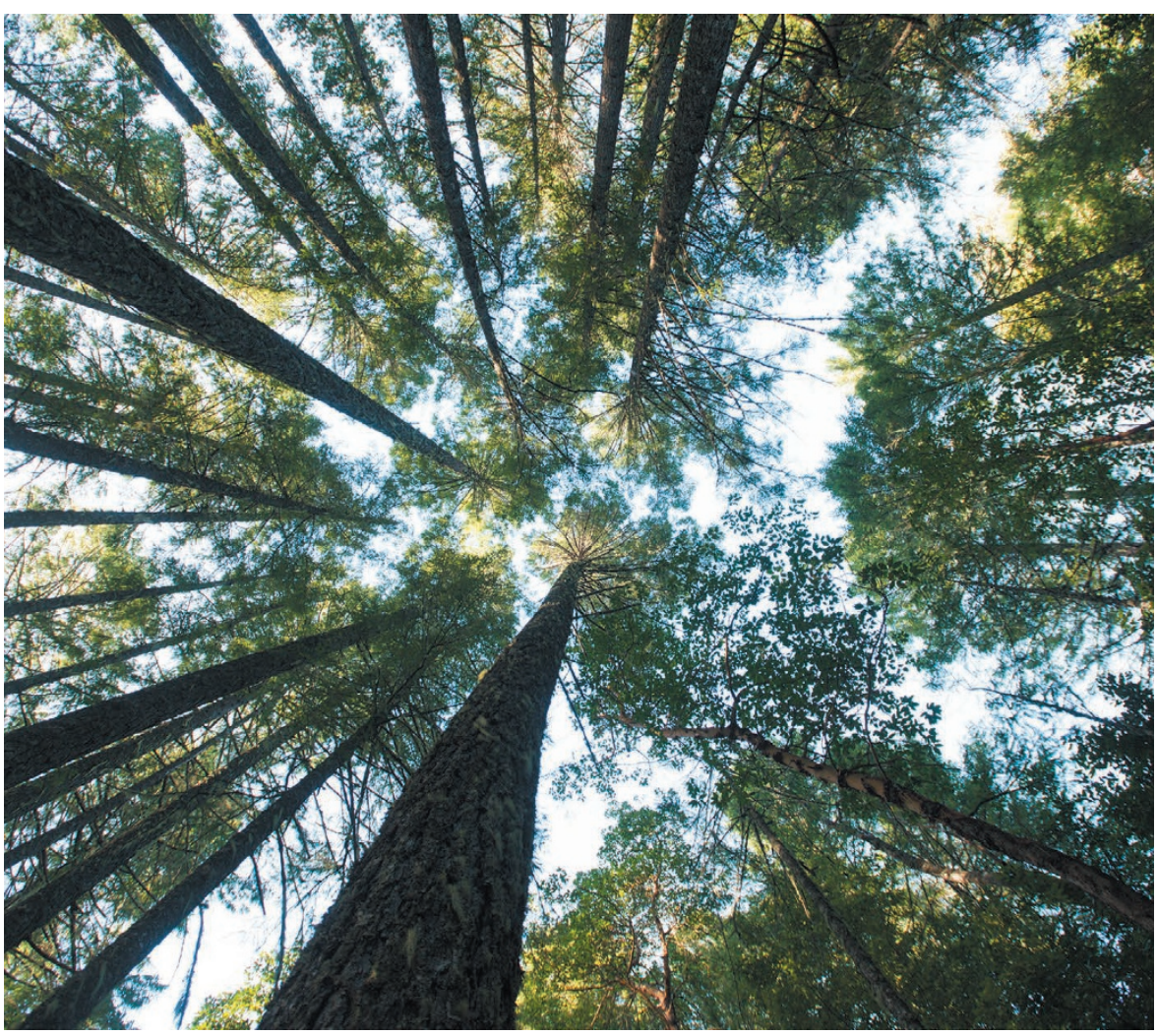

Trees communicate with each other using chemical signals carried on the breeze.

DENDROLOGY

\title{
The community of trees
}

\author{
Richard Fortey ponders a study that casts forests as \\ exquisitely complex, multistorey networks.
}

\section{$\mathrm{T}$} he Ents - the tree beings in J. R. R. Tolkien's The Lord of the Rings - conducted leisurely conversations that ignored mere human timescales. Years might pass to allow their deeper ruminations. Tolkien understood that arboreal time plays out over centuries. The Ents also had moral values and took sides, and were capable of exercising will, forging alliances and showing affection. After reading The Hidden Life of Trees, I suspect that German forester Peter Wohlleben regards beeches, his favourite trees, as not unlike Ents.

Much new science has been woven into this engaging natural history. Trees are networkers. Far from the solitary splendour of the ancient old stager, it turns out that trees communicate with one another through their roots. Underground fungi mycorrhizae associated with the root network - form a sort of subterranean internet that connects trees, passing messages and even nourishment between neighbours. Nor do trees passively tolerate the onslaught of insects on their tasty young leaves. Chemical

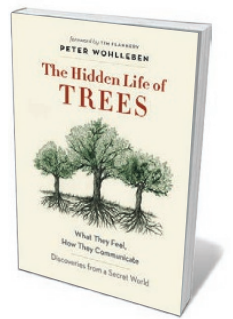

The Hidden Life of Trees: What They Feel, How They

Communicate -

Discoveries from a Secret World

PETER WOHLLEBEN Greystone: 2016 signals carried on the breeze from infested trees cause forest fellows to crank up their own chemical armouries. It's not a case of every tree for itself: the forest can behave as a single entity when it yields a great crop of acorns or beechnuts, or lies fallow for a year. Trees share a common response to weather and nourishment.

The hidden network allows for the nurturing of small trees in the understorey, where too little light penetrates for effective photosynthesis. The 'children' of a 'parent' tree bide their time until the oldster topples and the understorey underdogs at last get the chance to reach for the skies. Wohlleben's capable description of the leisurely drama of the forest through generations of trees idealizes an ecological progression too often interrupted by human felling and woodland management. It seems that trees are both more cooperative within a species and more complicated within a lifetime than prejudice might allow.

Wohlleben's vision of life among the trees has been developed during his decades-long stewardship of a chunk of forest dominated by beech in the Eifel, a mountain range straddling Germany and Belgium. He clearly desires woodlands to return to a state in which the slow life cycles of the trees are allowed to run without interference - a regrowth of the European 'wildwood' that grew up as the climate recovered after the retreat of the last Ice Age. He presents this as a golden age of arboreal life. Trees age at their own pace and die, to be replaced by 'family' that has been sheltering in their shadows for many years, nurtured on the mycelial teat. It's a kind of utopia for Ents. Not one such undisturbed ancient forest survives in Europe, except possibly in the Białowieża Forest of Poland. In Britain, woods have been managed since the Iron Age.

Whatever the virtues of this scenario, I have problems with Wohlleben's narrative approach. He describes trees as if they possessed consciousness. During times of drought they make "cries of thirst" or "might be screaming out a dire warning to their colleagues". They experience "rising panic". A seedling's growth is portrayed as fratricide as it sees off its siblings. It is rather extraordinary to read a book centred on co-evolution without a mention of natural selection. After a while, the urge to attribute motivation to the behaviour of trees becomes irksome. It is not so far away from hugging trees to connect to a supposed deeper reality.

Wohlleben sets out his stall quite specifically: "The distinction between plant and animal is, after all, arbitrary." Well, no, it's not. It has been a fact of phylogenetic separation for more than 1.7 billion years, during which exceedingly long time the two kingdoms have followed their own paths. Yes, problems in common require comparable solutions: communication and nutrition are universals, as scholars such as the plant biochemist Anthony Trewavas have shown. It is of selective advantage to trees to share news of insect threats, just as antelope respond together to the twitch of a lion's tail.

Trees are splendid and interesting enough in their own right without being saddled with a panoply of emotions. The anthropomorphism in this otherwise compelling book is more spice than it needs. Trees ain't Ents.

Richard Fortey is a research associate at the Natural History Museum, London. His latest book is The Wood for the Trees, an essay on the history and natural history of a small English beechwood. e-mail:r.fortey@nhm.ac.uk 